\title{
Center-Based Child Extended Care: Implications for Young Children's Development in a Five-Year Follow-Up
}

\author{
Tokie Anme ${ }^{1}$, Emiko Tanaka ${ }^{1}$, Ryoji Shinohara ${ }^{1}$, Yuka Sugisawa ${ }^{1}$, \\ Taeko Watanabe ${ }^{1}$, Etsuko Tomisaki ${ }^{1}$, Uma A. Segal ${ }^{2}$ \\ ${ }^{1}$ University of Tsukuba, Tsukuba, Japan \\ ${ }^{2}$ University of Missouri, St. Louis, USA \\ Email: tokieanme@gmail.com
}

Received March $30^{\text {th }}, 2012$; revised May $17^{\text {th }}, 2012$; accepted May $28^{\text {th }}, 2012$

\begin{abstract}
Effects of early extended child care on children's functioning from age one year through the end of year six were examined in the Japan Child Care Cohort Study. This longitudinal project sought to assess the developmental and adaptation effects on children. Parents completed a survey on the childrearing environment at home, their feelings of self-efficacy, and the available support for childcare. Childcare professionals evaluated the development of children. The results, using a panel cohort method, indicated that although parenting was a stronger and more consistent predictor of children's development than was the early extended child-care experience, support from the spouse predicted higher vocabulary development.
\end{abstract}

Keywords: Extended Child Care; Child Development; Child Rearing Environment; Self-Efficacy

\section{Introduction}

Large numbers of children in Japan experience routine nonmaternal child care during their infant, toddler, and preschool years. In 2011, 2.1 million (33.1\%) Japanese children, under the age of five years, were in child care (Ministry of Health, Labour and Welfare, 2011). The increased number of working mothers has led to the dramatic expansion of center-based child care. As nonmaternal child care has become more common, researchers and policy makers have become increasingly concerned about its effects on children's development (Belsky, 1988, 2001; Clarke-Stewart, 1989; Greenspan, 2003). Highquality center-based extended care is essential for children whose parents are employed in long hours that also include the evening and night hours.

Some researchers have highlighted potentially beneficial consequences of early child care, especially of high-quality care, on social functioning (Peisner-Feinberg, 1997; Vandell, 1988), as well as on cognitive-linguistic development or academic achievement (Broberg, 1997; Burchinal, 2000). Others have mentioned potentially adverse consequences, especially of long hours of care initiated early in life, on socioemotional functioning, including the emergence of behavior problems (Belsky, 2001; Vandell, 1990). Moreover, some have contended that child-care "effects," whether beneficial or detrimental, do not endure beyond the preschool or early elementary school years (Blau, 1999; Colwell, 2001; Deater-Deckard, 1996; Egeland, 1995), whereas others have claimed that child-care "effects" are more long lasting (Belsky, 1988; Vandell, 1990) or endure for some time, at least in the case of low-income children in highquality care (Campbell, 2001).

While studies of nonmaternal care are prevalent, there is less empirical information regarding the effects of placing children in nonmaternal care for long periods of time $(11+$ hours $)$. Few studies have assessed the influence of center-based extended care on child development (Anme, 2010). Therefore, in the present work, we used panel cohort data from the Japan Child Care Cohort to ascertain whether the amount of time and child rearing environment affected children's social competence or vocabulary/motor/intelligence development after five years.

\section{Methods}

\section{Setting and Sample}

All authorized child-day-care centers across Japan participated in the study. Centers unauthorized by the government were excluded as they often do not cooperate with external investigators. The subjects were all parents and service providers in the authorized facilities. Parents who had a one-year-old child were surveyed regarding the home environment, and service providers evaluated the development of each child in the facility. The valid response rate was $71.5 \%$ (1242) both for parents and service providers. Children with diagnosed disabilities and health problems were excluded from the study as these characteristics were expected to confound results. Of the 1242 children sampled at age one, 888 were sampled again at age five years, with both parents and service-providers evaluating the children. Table 1 provides the gender and age composition of the child population that was evaluated and the family structure, siblings, economic status, type of child care, and occupations of the parents. The distribution of boys, 449 (50.6\%), and girls, 439 (49.4\%), was fairly even.

\section{Overview of Measures}

Indicators of child-care quantity, quality, stability, and type (normal vs long) along with measures of family background, mothering, child characteristics and child adaptation to center-based care were obtained from questionnaires completed by the parents responsible for the children in the first six years of their lives (Appendix 1). Parents completed Japanese versions of questionnaires on the child-rearing environment (Caldwell, 
Table 1.

Demographic background of subjects.

\begin{tabular}{|c|c|c|}
\hline Variable & $\mathrm{n}$ & $\%$ \\
\hline \multicolumn{3}{|l|}{ Gender } \\
\hline Male & 449 & 50.6 \\
\hline Female & 439 & 49.4 \\
\hline \multicolumn{3}{|l|}{ Family structure } \\
\hline \multicolumn{3}{|l|}{ Nuclear family } \\
\hline Parents & 666 & 90.1 \\
\hline Mother only & 70 & 9.5 \\
\hline Father only & 3 & 0.4 \\
\hline \multicolumn{3}{|l|}{ Extended family } \\
\hline Parents + grandparents & 83 & 55.7 \\
\hline Mother + grandparents & 21 & 14.1 \\
\hline Others & 45 & 30.2 \\
\hline \multicolumn{3}{|l|}{ Siblings } \\
\hline None & 482 & 54.3 \\
\hline One or more & 406 & 45.7 \\
\hline \multicolumn{3}{|l|}{ Economic status } \\
\hline Below tax payment minimum & 432 & 48.6 \\
\hline Others & 55 & 6.2 \\
\hline N.A. & 398 & 44.8 \\
\hline \multicolumn{3}{|l|}{ Length of child care } \\
\hline$<11 \mathrm{~h}$ & 563 & 63.4 \\
\hline $11+h$ & 325 & 36.6 \\
\hline Total & 888 & 100.0 \\
\hline
\end{tabular}

1984) and on self-efficacy and support for childcare (Anme, 1990, 1995).

Childcare professionals, the service providers, evaluated children's social competence, communication, and development in vocabulary/motor/intelligence for each child using developmental scales standardized in Japan (Tumori, 1974). All childcare professionals, already qualified in child development, were provided with a minimum of eight hours of training to translate children's development into the measures indicated on the child development scale.

The two categories of childcare were identified by the time at which children left the center-based care: "normal care" (use of center-based care for less than 11 hours), and "long care" (use of center-based care for 11 or more hours). Of the subjects, 563 $(63.4 \%)$ were enrolled in "normal care" and $325(36.6 \%)$ in "long care."

Family and child variables included the child's gender and age, child development, parent behavior, parent efficacy for care, and the existence of childcare support. Professional caregivers, who participated in a six-hour training session on how to use the developmental scale, measured child development along six variables (gross and fine motor skills, social competence, communication, vocabulary, and intelligence development) that were categorized into 2-point items [(normal, delayed) Tumori, 1974] (See Table 2). These caregivers/service providers in the center-based childcare facilities also evaluated the health and disabilities of the children.

Parent behavior was assessed based on dichotomous responses (yes/no) to thirteen activities in the home environment. For analysis, the 25 th percentile point was used as a cut-off for non-nominal items. Parents provided self reports on a five-point scale, (where $1=$ always, $2=$ often, $3=$ sometimes, $4=$ rarely, $5=$ never) to indicate their feelings of efficacy for care (Anme, 1998) and which reflected the parent's affective state. Emotions evaluated were depression, anxiety, instability, stress, and exhaustion.

\section{Results}

The difference between the two types of care was examined by using items of child development, positive qualities of parents' behavior, parent efficacy for care, and existence of support for care. The Statistical Analysis System (SAS) statistical package was used for analysis. Multiple regression analysis was used to predict child development (delayed or normal) and child adaptation to center-based care (adapted or not) after five years using independent variables such as types of care ("night care" or else), positive qualities of parents' behavior (measured using 13 items), parent efficacy for care, and existence of support for care. Odds ratio was calculated to clarify the magnitude of effects. Odds ratio was calculated by multiple logistic analysis to estimate the strength of relations. All results that were assessed significant at the $p<.01$ or $p<.05$ level, however, the variable "types of care" was not selected as a related variable in all analyses.

Table 2 reports the number of risks related to child development.

As indicated in Table 3, a chi-square test was applied to the data to assess child development five years later. Baseline fine motor skills, social competence and communication development was significantly related to intelligence development five years later. Support from spouse was significantly related to vocabulary and intelligence development five years later; appropriate response to mistakes was related to vocabulary development, support for child care was correlated with intelligence development, and communication with parents was associated with fine motor development.

Table 2.

Percentage of group at risk.

\begin{tabular}{ccccc}
\hline Variables & \multicolumn{2}{c}{ Risk } & \multicolumn{2}{c}{ Non-risk } \\
\cline { 2 - 5 } & $\mathrm{n}$ & $\%$ & $\mathrm{n}$ & $\%$ \\
\hline Gross motor skills & 17 & 1.9 & 871 & 98.1 \\
Fine motor skills & 16 & 1.8 & 872 & 98.2 \\
Social competence & 12 & 1.4 & 876 & 98.6 \\
Communication skills & 18 & 2.0 & 870 & 98.0 \\
Vocabulary development & 24 & 2.7 & 864 & 97.3 \\
Intelligence development & 18 & 2.0 & 870 & 98.0 \\
\hline
\end{tabular}


Table 3.

Significant correlations between baseline variables and development after 5 years.

\begin{tabular}{|c|c|c|c|c|c|c|c|c|}
\hline \multirow{2}{*}{ Independent variable } & \multirow{2}{*}{ Dependent variable } & \multicolumn{3}{|c|}{ Risk } & \multicolumn{3}{|c|}{ Non-risk } & \multirow[t]{2}{*}{$\chi^{2}$} \\
\hline & & $\mathrm{N}^{\mathrm{a}}$ & $n^{b}$ & $\%^{\mathrm{c}}$ & $\mathrm{N}$ & $\mathrm{n}$ & $\%$ & \\
\hline Gender & Fine motor & 439 & 13 & 2.9 & 449 & 3 & 0.7 & * \\
\hline Fine motor (baseline) & Intelligence development & 46 & 4 & 9.0 & 842 & 14 & 1.7 & ${ }^{*}$ \\
\hline Social competence (baseline) & Intelligence development & 58 & 5 & 8.6 & 830 & 13 & 1.6 & * \\
\hline Communication (baseline) & Intelligence development & 29 & 3 & 10.3 & 859 & 15 & 1.8 & * \\
\hline \multirow[t]{2}{*}{ Support from spouse (baseline) } & Vocabulary development & 59 & 4 & 6.8 & 829 & 24 & 2.4 & * \\
\hline & Intelligence development & 59 & 4 & 6.8 & 829 & 14 & 1.7 & * \\
\hline Appropriate response to mistakes (baseline) & Vocabulary development & 54 & 4 & 7.4 & 834 & 20 & 2.4 & * \\
\hline Support for child care (baseline) & Intelligence development & 201 & 8 & 4.0 & 687 & 10 & 1.5 & ${ }^{*}$ \\
\hline Communication with parents (baseline) & Fine motor & 39 & 3 & 7.7 & 849 & 13 & 1.5 & * \\
\hline
\end{tabular}

Note: ${ }^{*} 0.01 \leq p<0.05,{ }^{a}$ Number of children "at risk" or "not at risk" at baseline for the independent measures; "Number of children in each category ("at risk" or "not at risk") identified as being developmentally delayed on the dependent measure. ${ }^{\mathrm{c}}$ Percentage of children $(\mathrm{n} / \mathrm{N} \times 100)$.

Table 4 shows the results of multiple regression analysis. Support from the spouse was significantly related to vocabulary development five years later (odds ratio 4.07), appropriate response to mistakes was related to vocabulary development (odds ratio 4.35), and going to the park was related to fine motor development (odds ratio 2.90).

\section{Discussion}

The aims of this study were to assess whether children's experiences in early child care and parenting facilitated their later social and academic development. This paper represents the latest installment in the ongoing study of relations between experiences in child care in the first year of life and child development using data gathered in the Japan Child Care Cohort.

Two issues were addressed in this paper: 1) whether associations linking child functioning with child-care quantity continued to be evident after five years, and 2) whether associations between parenting at one-year-old and child development after five years continued over time. We found evidence of relations between parenting and child development, as well as evidence that parenting quality proved to be a far stronger and more consistent predictor of child development than was length of child-care experiences. Associations linking child-care experience with child development after five years were smaller in size and less pervasive than those associated with parenting. This is not surprising because such results are consistent with earlier study findings (Bacharach, 2003; Borge, 2004).

Some studies indicated that children who were placed in nonmaternal care in the first year of life were more advantaged relative to those who initiated into nonmaternal care in the second or third year (Jaffee, 2011). These findings that differed from those of the current study suggest that observed associations between the timing of entry into nonmaternal care and children's behavior and academic abilities can be confounded by additional family characteristics that could influence childcare choices and children's outcomes.
It is possible that evidence for main effects of the timing of placement in nonmaternal care is weak and inconsistent because these effects are qualified by interactions with child characteristics or family circumstances. Borge (2004) have shown that family characteristics such as maternal education, SES, and composite measures of family risk moderate the effect of nonmaternal care on children's aggression, emotional problems, and language ability. They show that nonmaternal care is a protective factor for children from socially disadvantaged families but is not associated with cognitive or behavioral outcomes for children from socially advantaged families. To the extent that these findings can be replicated, they may lend support to efforts to subsidize high quality child care for low income families and to expand programs like Early Head Start.

While interesting and raising questions about earlier studies, these conclusions are preliminary and need to be tested more rigorously before they can advance theory and inform policy. The study may be benefit from replication. In addition, continued monitoring of the current sample may provide further insight into the longer-term effects as children move through the education system. Future studies may seek to assess not only child development but correlations between the independent variables and child behavior and adaptation to school and other environments.

Examination of social and intelligence functioning in preschool represents an important next step in understanding the relations between child care and developmental outcomes. Future research will need to focus on classroom and playground dynamics instead of focusing solely on individual child outcomes.

\section{Acknowledgements}

We express our deepest gratitude to Japan Night Child Care Alliance, President Amahisa, Vice-President Edamoto, all the participants and staffs.

This research was supported by the Grants-in-Aid for Scien- 
Table 4.

Correlation with risk factors following four year in care (multiple regression analysis includes all items — see below).

\begin{tabular}{|c|c|c|c|c|c|c|c|c|c|c|c|c|c|c|c|c|}
\hline \multirow{3}{*}{$\frac{\text { Variables }}{\text { Length of child care }}$} & \multicolumn{6}{|c|}{ Gross motor } & \multicolumn{5}{|c|}{ Fine motor } & \multicolumn{5}{|c|}{ Vocabulary development } \\
\hline & \multirow{2}{*}{$\frac{\text { Category }}{11+\mathrm{h}}$} & \multirow{2}{*}{$\begin{array}{c}\text { Odds ratio } \\
0.69\end{array}$} & \multirow{3}{*}{$\frac{p}{\mathrm{NA}}$} & \multicolumn{3}{|c|}{$95 \%$ range } & \multirow{2}{*}{$\frac{\text { Odds ratio }}{0.56}$} & \multirow{3}{*}{$\begin{array}{l}p \\
\text { NA }\end{array}$} & \multicolumn{3}{|c|}{$95 \%$ range } & \multirow{2}{*}{$\begin{array}{c}\text { Odds ratio } \\
1.20\end{array}$} & \multirow{3}{*}{$\frac{p}{\mathrm{NA}}$} & \multicolumn{3}{|c|}{$95 \%$ range } \\
\hline & & & & 0.221 & - & 2.119 & & & 0.170 & - & 1.839 & & & 0.503 & - & 2.881 \\
\hline & $<11 \mathrm{~h}$ & 1 & & & & & 1 & & & & & 1 & & & & \\
\hline \multirow[t]{2}{*}{ Gender } & Male & 2.12 & \multirow{2}{*}{ NA } & 0.749 & - & 6.007 & 3.90 & \multirow[t]{2}{*}{ * } & \multirow[t]{2}{*}{1.061} & \multirow[t]{2}{*}{ - } & \multirow[t]{2}{*}{14.309} & 1.13 & \multirow{2}{*}{ NA } & 0.479 & - & 2.651 \\
\hline & Female & 1 & & & & & 1 & & & & & 1 & & & & \\
\hline \multirow[t]{2}{*}{ Siblings } & None & 0.85 & \multirow{2}{*}{ NA } & 0.303 & - & 2.392 & 1.21 & \multirow{2}{*}{ NA } & 0.421 & - & 3.472 & 0.84 & & 0.363 & - & 1.946 \\
\hline & $\begin{array}{c}\text { One or } \\
\text { more }\end{array}$ & 1 & & & & & 1 & & & & & 1 & NA & & & \\
\hline Reading books & Rare & 0.35 & NA & 0.042 & - & 2.970 & 1.75 & $N$ & 0.422 & - & 7.252 & 2.04 & NA & 0.678 & - & 6.125 \\
\hline & Other & 1 & & & & & 1 & & & & & 1 & & & & \\
\hline Sing song together & Rare & - & Not & - & - & - & 1.06 & $\mathrm{~N}$ & 0.087 & - & 12.759 & - & Na & - & - & - \\
\hline & Other & 1 & & & & & 1 & $1012-1$ & & & & 1 & 101 & & & \\
\hline Support by spouse & Rare & 2.80 & $\mathrm{NA}$ & 0.467 & - & 16.841 & 1.03 & $\mathrm{NA}$ & 0.105 & - & 10.088 & 4.07 & $*$ & 1.023 & - & 16.713 \\
\hline & Other & 1 & & & & & 1 & & & & & 1 & & & & \\
\hline At least one meal with & Rare & - & NA & - & - & - & 2.33 & NA & 0.219 & - & 24.822 & 1.21 & $\mathrm{NA}$ & 0.130 & - & 11.243 \\
\hline parents & Other & 1 & & & & & 1 & & & & & 1 & & & & \\
\hline Appropriate & Risk & 2.29 & $\mathrm{NA}$ & 0.201 & - & 26.042 & 0.78 & NA & 0.083 & - & 7.229 & 4.35 & $*$ & 1.166 & - & 16.195 \\
\hline response to mistakes & Non-risk & 1 & & & & & 1 & & & & & 1 & & & & \\
\hline & Risk & 0.24 & & 0.054 & - & 1.046 & 0.85 & & 0.275 & - & 2.638 & 0.58 & & 0.219 & - & 1.541 \\
\hline & Non-risk & 1 & & & & & 1 & & & & & 1 & & & & \\
\hline Going grocery store & Rare & 0.79 & NA & 0.078 & - & 8.040 & - & NA & - & - & - & - & NA & - & - & - \\
\hline together & Other & 1 & & & & & 1 & & & & & 1 & & & & \\
\hline Going park with & Rare & 2.90 & * & 1.023 & - & 8.222 & 0.56 & NA & 0.148 & - & 2.134 & 0.89 & * & 0.344 & - & 2.327 \\
\hline child & Other & 1 & & & & & 1 & & & & & 1 & & & & \\
\hline Going friend's house & Rare & 1.24 & $N$ & 0.449 & - & 3.418 & 0.77 & $N$ & 0.263 & - & 2.251 & 1.30 & & 0.562 & - & 2.999 \\
\hline & Other & 1 & 107 & & & & 1 & & & & & 1 & & & & \\
\hline Sunnort for child care & No & 1.88 & $N A$ & 0.614 & - & 5.767 & 0.73 & $N A$ & 0.179 & - & 3.015 & 0.84 & & 0.286 & - & 2.463 \\
\hline gар & Yes & 1 & 107 & & & & 1 & 101 & & & & 1 & 101 & & & \\
\hline Concultotion & No & 0.58 & NA & 0.058 & - & 5.815 & 2.58 & & 0.375 & - & 17.789 & 0.94 & & 0.103 & - & 8.597 \\
\hline 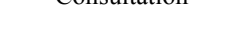 & Yes & 1 & 101 & & & & 1 & 101 & & & & 1 & 1012 & & & \\
\hline Talking with spouse & Rare & 2.02 & NA & 0.226 & - & 18.026 & 3.76 & NA & 0.374 & - & 37.794 & 0.99 & NA & 0.141 & - & 6.908 \\
\hline about child & Other & 1 & & & & & 1 & & & & & 1 & & & & \\
\hline Confidence for child & Rare & 3.10 & $\mathrm{NA}$ & 0.529 & - & 18.150 & 3.20 & NA & 0.720 & - & 14.166 & 0.64 & & 0.073 & - & 5.576 \\
\hline care & Other & 1 & & & & & 1 & 20 & & & & 1 & (2) & & & \\
\hline
\end{tabular}

Note: ${ }^{*} 0.01 \leq p<0.05$; Input items: length of child care, gender, sibling, play with child, reading books, sing song together, support by spouse, at least one meal with parents, appropriate response to mistakes, punishment, going grocery store together, going park together, going friend's house, support for child care, consultation, talking with spouse about child, confidence for child care, adaptation for center based care, age of start for center based care, fine motor (baseline) - a, social competence (baseline) - b, vocabulary (baseline) — $c{ }^{*}(\mathrm{a}-\mathrm{c})$ baseline variable was only input when that particular variable was being assessed.

tific Research (23330174) and Research Institute of Science and Technology for Society.

\section{REFERENCES}

Anme, T. (1995). Risk assessment using evaluation of environmental stimulation in Japan. National Roundtable on Child Protective Ser- vices Risk Assessment, 9, 37-47.

Anme, T., \& Uma, S. (2010). Effectiveness of Japan's extended/night child care: A five-year follow up. Procedia Social and Behavioural Sciences, 2, 5573-5580. doi:10.1016/j.sbspro.2010.03.909

Anme, T., \& Takayama, T. (1990). Evaluation of home stimulation for normal and handicapped children in Japan. In T. Takayama (Ed.), Early childhood toward the 21st century (pp. 427-430). Hong Kong: Yew Chung Education Publishing Company. 
Bacharach, V. R., \& Baumeister, A. A. (2003). Child care and severe externalizing behavior in kindergarten children. Applied Developmental Psychology, 23, 527-537. doi:10.1016/S0193-3973(02)00140-5

Belsky, J. (1988). The "effects" of infant day care reconsidered. Early Childhood Research Quarterly, 3, 235-272. doi:10.1016/0885-2006(88)90003-8

Belsky, J. (2001). Developmental risks (still) associated with early child care. Journal of Child Psychology and Psychiatry, 42, 845-859. doi:10.1111/1469-7610.00782

Blau, D. (1999). The effects of child care characteristics on child development. Journal of Human Resources, 34, 786-822.

doi:10.2307/146417

Borge, A. I., Rutter, M., Cote, S., \& Tremblay, R. E. (2004). Early childcare and physical aggression: Differentiating social selection from social causation. Journal of Child Psychology and Psychiatry, 45, 367-376. doi:10.1111/j.1469-7610.2004.00227.x

Broberg, A. G., Wessels, H., Lamb, M. E., \& Hwang, C. P. (1997). Effects of day care on the development of cognitive abilities in 8-year-old: A longitudinal study. Developmental Psychology, 33, 6269. doi:10.1037/0012-1649.33.1.62

Burchinal, M. R., Roberts, J. E., Riggins, R., Zeisel, S., Neebe, E., \& Bryant, M. (2000). Relating quality of center child care to early cognitive and language development longitudinally. Child Development, 71, 339-357. doi:10.1111/1467-8624.00149

Caldwell, B. M., \& Bradley, R. H. (1984). Home observation for measurement of the environment. Little Rock: University of Arkansas at Little Rock.

Campbell, F. A., Pungello, E. P., Miller-Johnson, S., Burchinal, M. R., \& Ramey, C. (2001). The development of cognitive and academic abilities: Growth curves from an early intervention educational experiment. Developmental Psychology, 37, 231-242.

doi:10.1037/0012-1649.37.2.231

Clarke-Stewart, K. A. (1989). Infant day care: Maligned or malignant?
American Psychologist, 44, 266-273.

doi:10.1037/0003-066X.44.2.266

Colwell, M., Pettit, G., Meece, D., Bates, J. E., \& Dodge, K. A. (2001) Cumulative risk and continuity in nonparental care from infancy to early adolescence. Merrill-Palmer Quarterly, 47, 207-234. doi:10.1353/mpq.2001.0009

Deater-Deckard, K. A., Pinkerton, R., \& Scarr, S. (1996). Child care quality and children's behavioral adjustment: A four-year longitudinal study. Journal of Child Psychology and Psychiatry, 37, 937-948. doi:10.1111/j.1469-7610.1996.tb01491.x

Egeland, B., \& Hiester, M. (1995). The long-term consequences of infant day-care and mother-infant attachment. Child Development, 66, 474-485. doi: $10.2307 / 1131591$

Greenspan, S. I. (2003). Child care research: A clinical perspective. Child Development, 74, 1064-1068. doi:10.1111/1467-8624.00591

Jaffee, S. R., Hulle, C. V., \& Rodgers, J. L.(2011). Effects of nonmaternal care in the first 3 years on children's academic skills and behavioral functioning in childhood and early adolescence: A sibling comparison study. Child Development, 82, 1076-1091. doi:10.1111/j.1467-8624.2011.01611.x

Ministry of Health, Labour and Welfare (2011). Fact sheet of child care 2011.

http://www.mhlw.go.jp/english/org/pamphlet/dl/pamphlet-about mhl w.pdf\#page $=24$

Peisner-Feinberg, E., \& Burchinal, M. (1997). Concurrent relations between child care quality and child outcomes: The study of cost, quality and outcomes in child care centers. Merrill-Palmer Quarterly, 43, 451-477.

Tumori, S. (1974). Developmental evaluation. Kyusu: Kyusu Daigaku Syuppan.

Vandell, D. L., Henderson, V. K., \& Wilson, K. S. (1988). A longitudinal study of children with day-care experiences of varying quality. Child Development, 59, 1286-1292. doi:10.2307/1130491 


\section{Appendix 1. Questionnaire (Extract)}

1. How often do you play with your child per week?

1) rarely 2) 1 - 2 weeks 3) 3-4 weeks 4) 5 - 6 weeks

5) almost every day 6) other ( )

2. How often do you go shopping with your child?

1) rarely 2) 1-2 months 3) 1-2 weeks 4) 3-4 weeks

5) almost every day 6) other ( )

3. How often do you read to your child?

1) rarely 2) 1-2 months 3) 1 - 2 weeks 4) 3-4 weeks

5) almost every day 6) other ( )

4. How often do you sing songs with your child?

1) rarely 2) 1 - 2 months 3) 1 - 2 weeks 4) 3 - 4 weeks

5) almost every day 6) other ( )

5. How often do you go to the park with your child?

1) rarely 2) 1-2 months 3) 1-2 weeks 4) 3-4 weeks

5) almost every day 6) other ( )

6. How often do you and your child meet with friends or relatives with children of a similar age?

1) rarely 2) 1 - 2 months 3) 1 - 2 weeks 4) 3 - 4 weeks

5) almost every day 6) other ( )

7. How often does your spouse, partner, or other care giver help you with the child?

1) rarely 2) 1 - 2 months 3) 1 - 2 weeks 4) 3 - 4 weeks

5) almost every day 6) other ( )

8. How often does your child eat meals together with both parents?
1) rarely 2) 1 - 2 months 3) 1-2 weeks 4) 3-4 weeks

5) almost every day 6) other ( )

9. What do you do if your child spills milk purposely?

1) hit the child 2) scold the child 3) discipline in another way 4) determine how to prevent it in the future

5) other ( )

10. How many times did you hit or kick your child last week?

1) never 2) 1 - 2 times 3) 3-4times 4) 4-5 times

5) almost every day 6) other ( )

11. How many times do you have a chance to talk with your partner about your child?

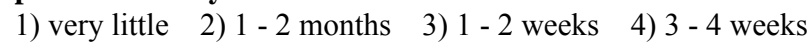

5) almost every day 6) other ( )

12. Does someone help you take care of your child?

1) Yes 2) No 3) other ( )

If yes, circle all the following that apply:

1) spouse 2) grandparent 3) friend 4) relative

5) neighbor 6) child care professionals from the nursery

7) director of nursery 8) baby-sitter 9) other staff at the nursery 10) other ( )

13. Do you have someone to consult with about childcare?

1) Yes 2) No 3) other ( )

If yes, circle all the following that apply:

1) spouse 2) grandparent 3) friend 4) relative

5) neighbor 6) child care professionals from the nursery

7) director of nursery 8) baby-sitter 9) other staff at the nursery 10) other ( ) 